University of South Carolina

Scholar Commons

$10-28-2014$

\title{
Host-Guest Interaction Dictated Selective Adsorption and Fluorescence Quenching of a Luminescent lightweight Metal- Organic Framework toward Liquid Explosives
}

\author{
Dan Liu \\ Xiaojuan Liu \\ Yongxin Liu \\ Yang Yu \\ Fanglin Chen \\ University of South Carolina - Columbia, chenfa@cec.sc.edu
}

Seldorexthisadyedfaddidtitiah

Part of the Applied Mechanics Commons, Heat Transfer, Combustion Commons, and the Other Mechanical Engineering Commons

\section{Publication Info}

Published in Dalton Transactions, Volume 43, Issue 40, 2014, pages 15237-15244.

(C)Dalton Transactions 2014, Royal Society of Chemistry.

This article cannot be redistributed or further made available. This article was first published by the Royal Society of Chemistry and can be found at http://dx.doi.org/10.1039/C4DT01883D

Liu, D., Liu, X., Liu, Y., Yu, Y., Chen, F., \& Wang, C. (28 October 2014). Host-Guest Interaction Dictated Selective Adsorption and Fluorescence Quenching of a Luminescent lightweight Metal-Organic Framework toward Liquid Explosives. Dalton Transactions, 43 (40), 15237 - 15244. http://dx.doi.org/ 10.1039/C4DT01883D

This Article is brought to you by the Mechanical Engineering, Department of at Scholar Commons. It has been accepted for inclusion in Faculty Publications by an authorized administrator of Scholar Commons. For more information, please contact digres@mailbox.sc.edu. 


\section{Author(s)}

Dan Liu, Xiaojuan Liu, Yongxin Liu, Yang Yu, Fanglin Chen, and Cheng Wang 


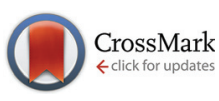

Cite this: Dalton Trans., 2014, 43, 15237

\section{Host-guest interaction dictated selective adsorption and fluorescence quenching of a luminescent lightweight metal-organic framework toward liquid explosives $\uparrow$}

Dan Liu, ${ }^{a}$ Xiaojuan Liu, ${ }^{a}$ Yongxin Liu, ${ }^{a}$ Yang Yu, ${ }^{a}$ Fanglin Chen ${ }^{b}$ and Cheng Wang ${ }^{\star a}$

In this article, we report the successful preparation of a $\mathrm{Mg}$-based luminescent MIL-53 metal-organic framework (MOF), namely $\left[\mathrm{Mg}_{2}(\mathrm{BDC})_{2}(\mathrm{BPNO})\right] \cdot 2 \mathrm{DMF}(\mathbf{1})\left(\mathrm{BDC}=1,4\right.$-benzene dicarboxylate, $\mathrm{BPNO}=4,4^{\prime}$ dipyridyl- $N, N^{\prime}$-dioxide, $D M F=N, N$-dimethylformamide) in a mixed solvent containing a $2: 3$ volume ratio of DMF and ethanol (EtOH) under solvothermal conditions. Desolvated compound 1a can be used as an absorbent for selective adsorption and separation of liquid explosives, including nitroaromatic (nitrobenzene (NB)) and nitroaliphatic (nitromethane (NM) and nitroethane (NE)) compounds, through single crystal-to-single crystal (SC-SC) transformations. As one of the weakly luminescent MOFs, the luminescence of compound 1a could be quenched by the incorporation of the three liquid nitro explosives. On the basis of single crystal analysis, we provide direct evidence that both the selective adsorption and fluorescence quenching of the desolvated compound $1 \mathbf{a}$ are dictated by host-guest interactions between guest liquid explosives and the host framework. Such findings differ from those reported in previous works, which were dominated by surficial close contact interactions. Moreover, based on the experimentally obtained single-crystal structures, we explain that the luminescence of 1a follows the intraligand $\pi^{\star} \rightarrow \pi$ emission states or weak ligand to ligand charge transfer (LLCT), with little incorporation of intraligand charge transfer (ILCT).

Received 23rd June 2014, Accepted 7th August 2014

DOI: $10.1039 /$ c4dt01883d

www.rsc.org/dalton usually with $\pi$-conjugated backbones, are mainly responsible for their abundant luminescence. ${ }^{2}$ The combination of porosity and luminescence in MOFs makes them potential candidates for the sensing of small molecules. ${ }^{3}$ The incorporation of a small molecular analyte into the pores of MOFs facilitates signal transductions between the framework and guests via host-guest interactions, including $\mathrm{H}$-bonds, $\pi \cdots \pi, \mathrm{C}-\mathrm{H} \cdots \pi$, anion $\cdots \pi$, etc., typically resulting in luminescence quenching. ${ }^{4}$

Rapid and selective detection of liquid explosives has become an increasingly important and urgent issue in modern society due to the heightened terrorist threat. ${ }^{5}$ Liquid explosives are an interesting group of explosive systems and very similar in many aspects to solid explosives. Liquid explosives can be roughly classified into three categories: (i) individual chemical compounds that are inherently explosive, (ii) mixtures of such compounds, and (iii) mixtures of chemicals which individually have no explosive properties, but as a mixture would have a rapid rate of reaction, generate a large amount of heat, and could be strong explosives. In particular, liquid nitroaromatic (nitrobenzene (NB)) and nitroaliphatic compounds, such as nitromethane (NM) and nitroethane (NE) are usually used as industrial chemicals for various purposes. Once in combination with particular components, 
they would be the important part of very strong, cap sensitive explosives.

In addition, the recent rise in global terrorism has required that explosive detection methods should be both highly sensitive and low-cost. Among the current detection technologies, fluorescence quenching based detection of explosives has grown enormously, owing to its high sensitivity, easy visualization and real-time monitoring with fast response time. ${ }^{6}$ Even though little attention has been given to the development of fluorescence-based detection for liquid nitro explosives in liquid-phase or vapor-phase, most of the fluorescence sensory materials (e.g., polymers) reported thus far usually respond to a class of solid nitroaromatics (NAC), rather than a single specific target. $^{7}$ Yet, because of the variety of explosive materials available, the cleverness of the packaging, the variability of venue, and the (mostly) high vapor pressures of explosives, the detection of liquid nitro explosives still remains very challenging for optical sensors. Very recently, increasing investigations have been made on the design of sensing devices based on luminescent MOFs for detection of solid nitro explosives, due to the aforementioned dual functionality of MOFs. The particle size of the investigated fluorescent MOF-type materials varied from micrometer to nanometer scale, ${ }^{8}$ and the encapsulation of large aromatic organic molecules, e.g., trinitrotoluene (TNT) and its degradation products 2,4-dinitrotoluene (DNT) and picric acid (PA), was excluded due to the small pore size of the reported MOFs. The sensing mechanism was proposed to originate from the close contact interactions between nitro explosives and small particles of MOFs.

Herein, we report a luminescent lightweight MOF, namely $\left[\mathrm{Mg}_{2}(\mathrm{BDC})_{2}(\mathrm{BPNO})\right] \cdot 2 \mathrm{DMF}(\mathbf{1})$ (BDC $=1,4$-benzene dicarboxylate, $\mathrm{BPNO}=4,4^{\prime}$-dipyridyl- $N, N^{\prime}$-dioxide, $\mathrm{DMF}=N, N$-dimethylformamide), as an adsorbent and sensor for selective adsorption and detection of liquid nitroaromatic (nitrobenzene (NB)) and nitroaliphatic (nitromethane (NM) and nitroethane (NE)) explosives in liquid-phase or vapor-phase. These findings show that the selective adsorption and/or separation capabilities of $\mathrm{Mg}$-based lightweight MOFs could be extended from mainly small molecular gases, e.g., $\mathrm{H}_{2}$ or $\mathrm{CO}_{2}$ to larger organic molecules. ${ }^{9}$ From a structural point of view, the pore size of desolvated 1 (1a) generally lies within the working distances of photoinduced electron transfer. Photophysically, the three small liquid nitro explosives incorporated into the pores can efficiently interact with the pore wall via $\pi-\pi$ interaction or/and hydrogen bonding interactions, which influences dramatic changes in the fluorescence quenching efficiency of the sensor. Based on the experimentally obtained single-crystal structures, we explain that the luminescence of 1a follows the intraligand $\pi^{*} \rightarrow \pi$ emission states or weak ligand to ligand charge transfer (LLCT), with little incorporation of intraligand charge transfer (ILCT).

In our previous studies, we have achieved the formation of transition metal based MIL-53 (abbreviated to $\mathbf{M}^{\mathrm{II}}$-MIL-53, M = $\mathrm{Mn}^{\mathrm{II}}$ and $\mathrm{Co}^{\mathrm{II}}$ ) analogues, using pyridine $N$-oxide and its derivatives as neutral ligands. ${ }^{10}$ The synthetic strategy was extended to the synthesis of compound $\mathbf{1}$ by altering the metal precursor and solvent. The MIL-53 $\left(\mathrm{M}^{\mathrm{III}}\right)$ system, firstly developed by Férey and co-workers under soft solvothermal conditions, possesses flexible frameworks. ${ }^{11}$ The typical structural topology of MIL-53 compounds consists of a $4^{4}$ net with chains of $\mathrm{M}^{\mathrm{III}} \mathrm{O}_{4}(\mathrm{OH})_{2}\left(\mathrm{M}^{\mathrm{III}}=\mathrm{Al}^{3+}, \mathrm{Ga}^{3+}, \mathrm{In}^{3+}, \mathrm{Fe}^{3+}, \mathrm{Cr}^{3+}\right.$ and so on) octahedra linked together via the carboxylate groups of the terephthalate ions. ${ }^{12}$ Along the chains of the $\mathrm{M}^{\mathrm{III}} \mathrm{O}_{4}(\mathrm{OH})_{2}$ octahedra, the adjacent metal centers share the $\mu_{2}-\mathrm{OH}$ groups. When replacing the $\mu_{2}-\mathrm{OH}$ by an oxygen atom ( $\mu_{2}$-oxo) or neutral ligand, the valence of the metal center should be changed to +4 or +2 accordingly in order to maintain a neutral framework. ${ }^{10,13}$

\section{Experimental section}

\section{Materials}

All chemicals were purchased from commercial sources and used without further purification, except for pyridine $N$-oxide. The pyridine $N$-oxide-based ligand (4,4'-bipyridine- $N, N^{\prime}$-dioxide (BPNO)) was prepared according to a reported process with minor modifications. ${ }^{21}$

\section{Characterization}

Elemental analyses were performed using a Perkin-Elmer 2400 elemental analyzer. Fourier transform infrared (FT-IR) spectra were recorded in the range of $400-4000 \mathrm{~cm}^{-1}$ on a PerkinElmer FT-IR spectrometer (PE430) using $\mathrm{KBr}$ pellets. Absorption peaks are described as follows: very strong (vs), strong (s), medium (m), and weak (w). Thermogravimetric analysis (TGA) was performed on a NETESCH STA $449 \mathrm{~F} 3$ instrument under a constant flow of $\mathrm{N}_{2}$ at a rate of $10{ }^{\circ} \mathrm{C} \mathrm{min}^{-1}$. The powder X-ray diffraction data (PXRD) were collected using a Bruker D8FOCUS diffractometer equipped with $\mathrm{Cu} \mathrm{K} \alpha 1(\lambda=1.5406 \AA$, $1600 \mathrm{~W}, 40 \mathrm{kV}, 40 \mathrm{~mA})$ at a scan speed of $5^{\circ} \mathrm{min}^{-1}$. The simulated PXRD patterns were calculated using single-crystal X-ray diffraction data and processed by the free Mercury v1.4 program provided by the Cambridge Crystallographic Data Center. The carbon dioxide adsorption-desorption isotherm was obtained on a Brunauer-Emmett-Teller (BET) surface area analyzer (ASAP-2020). Before measurements, compound 1 was degassed at $180{ }^{\circ} \mathrm{C}$ for about eight hours. The temperature of the measurements for $\mathrm{CO}_{2}$ was $273 \mathrm{~K}$. The fluorescence excitation and emission spectra were recorded on a Hitachi F-4500 spectrophotometer equipped with a $150 \mathrm{~W}$ xenon lamp as an excitation source at room temperature.

\section{Synthesis of $\left[\mathrm{Mg}_{2}(\mathrm{BDC})_{2}(\mathrm{BPNO})\right] \cdot 2 \mathrm{DMF}(1)$}

A mixture of $\mathrm{Mg}\left(\mathrm{NO}_{3}\right)_{2} \cdot 6 \mathrm{H}_{2} \mathrm{O}(0.1282 \mathrm{~g}, 0.5 \mathrm{mmol}), \mathrm{H}_{2} \mathrm{BDC}$ $(0.0330 \mathrm{~g}, 0.2 \mathrm{mmol})$, BPNO $(0.0565 \mathrm{~g}, 0.3 \mathrm{mmol})$ and a mixture of DMF and EtOH $(2 \mathrm{ml}: 3 \mathrm{ml})$ were added into a $15 \mathrm{ml}$ Teflon-lined stainless autoclave and heated at $120^{\circ} \mathrm{C}$ for $24 \mathrm{~h}$. After cooling to room temperature, yellow stick-shaped crystals suitable for X-ray analysis were formed directly, washed with DMF and dried in air. Yield: $77 \%$ based on $\mathrm{Mg}^{\mathrm{II}}$ salt. Elemental analysis (\%) calcd for 1: C 54.04, H 4.25, N 
7.88\%; found: C 53.95, H 4.21, N 7.91\%. IR ( $\left.\mathrm{KBr}, \mathrm{cm}^{-1}\right): 3433$ w, 3123 w, 1706 vs, 1575 vs, 1379 m, 1216 s, 844 m, 751 m.

\section{Removing guest DMF molecules from 1}

Two methods were developed to remove the DMF guest molecules. In the first case, the as-synthesized $\mathbf{1}$ was added to a flask that was connected to an oil pump and heated in an oil bath. The flask was heated at $150{ }^{\circ} \mathrm{C}$ for $8 \mathrm{~h}$ under vacuum. The second method was to soak a sample of $\mathbf{1}$ in a vial containing dichloromethane $\left(\mathrm{CH}_{2} \mathrm{Cl}_{2}\right)$ for one to two days. The original DMF molecules were replaced by $\mathrm{CH}_{2} \mathrm{Cl}_{2}$. Then the solvent from the soaked sample was allowed to evaporate under ambient conditions or removed using an oil pump at room temperature. The resultant product was termed as $\left[\mathrm{Mg}_{2}(\mathrm{BDC})_{2}(\mathrm{BPNO})\right] \mathbf{1 a}$, which is fairly stable in ambient atmosphere and can retain its single crystallinity upon exposure to air for more than one month. Elemental analysis (\%) calcd for 1a: C 55.27, H 2.85, N 4.96\%; found: C 54.77, H $2.93, \mathrm{~N} 4.88 \%$. (The large discrepancy of the carbon content between the calcd and found values might be due to the remnant DMF in 1a, as suggested from TG/DTA data in Fig. S5b. $\dagger$ ) IR (KBr, cm ${ }^{-1}$ ): 3425 w, 1588 vs, 1377 m, 1218 s, $844 \mathrm{~m}, 751 \mathrm{~m}$.

\section{Adsorptions of NB, NM and NE using 1a as absorbent via single-crystal to single-crystal transformations}

Single crystals of $\mathbf{1 a}$ were added into round-bottomed flasks containing $25 \mathrm{ml} \mathrm{NB}$, NM, or NE. It was found that NB, NM and $\mathrm{NE}$ molecules could be intercalated into $1 \mathrm{a}$ after $5 \mathrm{~h}$ immersion, giving $\left[\mathrm{Mg}_{2}(\mathrm{BDC})_{2}(\mathrm{BPNO})\right] \cdot 2 \mathrm{NB}(2),\left[\mathrm{Mg}_{2}(\mathrm{BDC})_{2}{ }^{-}\right.$ (BPNO)].2NM (3), and $\left[\mathrm{Mg}_{2}(\mathrm{BDC})_{2}(\mathrm{BPNO})\right] \cdot 2 \mathrm{NE}$ (4). Alternatively, 2-4 can be obtained by exposing 1 a to NB, NM and NE vapors for 3 days at $80^{\circ} \mathrm{C}$. Compound 2: IR ( $\mathrm{KBr}$ pellet, $\left.\mathrm{cm}^{-1}\right)$ : 3464 w, 3119 w, 1697 vs, 1658 vs, 1522 m, 1376 s, 1179 s, $856 \mathrm{~m}, 748 \mathrm{~m}$. Anal. Calcd for $\mathrm{C}_{38} \mathrm{H}_{26} \mathrm{Mg}_{2} \mathrm{~N}_{4} \mathrm{O}_{14}$ : C, 56.26; H, 3.23; N, 6.91\%. Found: C, 56.19; H, 3.18; N, 7.11\%. Compound 3: IR (KBr pellet, $\mathrm{cm}^{-1}$ ): $3471 \mathrm{w}, 3210 \mathrm{w}, 1658 \mathrm{vs,} 1522 \mathrm{~m}, 1296$ s, $864 \mathrm{~m}, 751 \mathrm{~m}$. Anal. Calcd for $\mathrm{C}_{28} \mathrm{H}_{22} \mathrm{Mg}_{2} \mathrm{~N}_{4} \mathrm{O}_{14}: \mathrm{C}, 48.94 ; \mathrm{H}$, 3.23 ; N, 8.15\%. Found: C, 48.33; H, 3.22; N, 8.11\%. (Again, the discrepancy of carbon content could be ascribed to the NM vacancy in 3.) Compound 4: $\mathrm{IR}\left(\mathrm{KBr}\right.$ pellet, $\left.\mathrm{cm}^{-1}\right)$ : $3479 \mathrm{w}$, 3118 w, 1704 vs, 1658 vs, 1522 m, 1397 s, 1304 s, 878 m, 751 m. Anal. Calcd for $\mathrm{C}_{30} \mathrm{H}_{26} \mathrm{Mg}_{2} \mathrm{~N}_{4} \mathrm{O}_{14}: \mathrm{C}, 50.38$; H, 3.66; N, 7.83\%. Found: C, 50.29; H, 3.62; N, 7.79\%.

\section{Regeneration of 1 after adsorption of NB, NM and NE}

To regenerate crystal 1, crystals of 2, 3 and 4 were immersed in DMF in sample vials open to the air at RT for two weeks, products $2^{\prime}, 3^{\prime}$ and $4^{\prime}$ were harvested, respectively. X-ray structural analysis of $2^{\prime}, 3^{\prime}$ and $4^{\prime}$ revealed that original crystals of 1 could be regenerated.

\section{Single-crystal studies}

Suitable single crystals of $1,1 \mathrm{a}, 2,2^{\prime}, 3,33^{\prime}, \mathbf{4}$ and $\mathbf{4}^{\prime}$ were collected on a Bruker SMART Apex-II CCD diffractometer with graphite monochromatized Mo-K $\alpha$, radiation $(\lambda=0.71073 \AA)$ operating at $1.575 \mathrm{~kW}(45 \mathrm{kV}, 35 \mathrm{~mA})$ at low temperature ( 1 at $293 \mathrm{~K}$, and the others at $273 \mathrm{~K}$ ). The linear absorption coefficients, scattering factors for the atoms, and anomalous dispersion corrections were taken from International Tables for X-ray Crystallography. All intensity data were corrected for Lorentz and polarization effects, and empirical absorption corrections based on equivalent reflections were applied (SADABS). The structures were solved by direct methods and refined by the full-matrix least-squares method on $F^{2}$ with SHELXTL program package. ${ }^{22}$ All non-hydrogen atoms were refined with anisotropic displacement parameters. The $\mathrm{H}$ atoms were generated geometrically. X-ray data are given in Table S2. $\dagger$

\section{Results and discussion}

\section{Synthesis and activation}

For growing single crystals under hydro-(solvo)thermal conditions, solvent plays an essential role since it determines the solubility of the precursor or/and final product, which exerts dramatic influence on the nucleation and subsequent crystal growth process. In this work, the synthetic protocol was modified from our previously reported synthesis of $\mathrm{Mn} / \mathrm{Co}$-based MIL-53. ${ }^{10}$ Briefly, compound 1 was prepared solvothermally using similar procedures except for the changes to the metal salt and solvent. Typically, the reaction between $\mathrm{Mg}$ $\left(\mathrm{NO}_{3}\right)_{2} \cdot 6 \mathrm{H}_{2} \mathrm{O}$ and a mixture of BPNO and BDC ligands in a mixed solvent of DMF and EtOH (2:3 volume ratio of DMFEtOH) afforded 1. Previously, in the synthesis of Mn/Co-MIL-53 compounds, only pure DMF was used. However, product 1 could not be obtained under similar conditions. With the addition of EtOH, crystals of 1 suitable for single crystal X-ray characterization could be produced. We attempted to use methanol or propanol to replace EtOH in the synthesis, but this turned out to be unsuccessful. It should be mentioned that compound 1 could not be obtained using either of the three pure alcohols. We also investigated the effect of the volume ratio of DMF to EtOH on the synthesis. The optimized volume ratio was found to be in the range of $2: 3$ to $4: 1$. Beyond this range, only very small crystals, unsuitable for single-crystal X-ray diffraction characterization, with much lower yield were obtained. Compound $\mathbf{1}$ is insoluble in most organic solvents except for water, which allows the study of SC-SC transformation reactions here.

Despite both EtOH and DMF being used in the synthesis, only DMF was found in 1. In order to completely remove the occluded DMF molecules from 1, the temperature of the oil bath should be greater than $150{ }^{\circ} \mathrm{C}$ during the desolvation process. For its two analogues, Mn/Co-MIL-53, their desolvation temperature via a similar treatment should be less than $120^{\circ} \mathrm{C}$, otherwise these two compounds tend to pulverize and lose their crystallinity. This observation suggests that the thermal stability of $\mathbf{M}^{\text {II }}$-MIL-53 ( $\mathbf{M}=\mathbf{M n}$, Co or $\mathrm{Mg}$ ) was increased when the metallic centers were changed from transition metals to main group magnesium metal. Meanwhile, 
the desolvation and reinsertion of DMF molecules is reversible for at least four cycles.

\section{Structure description}

Single-crystal X-ray diffraction analysis revealed that compound 1 (also referred to as Mg-MIL-53) is isostructural to Mn/ Co-MIL-53. It crystallizes in the same space group of $C 2 / c$ and has unit cell parameters close to their values (see Table $\mathrm{S} 1 \dagger$ ). Briefly, compound $\mathbf{1}$ was constructed from infinite chains of corner-sharing $\mathrm{MgO}_{6}$ octahedra (four oxygen atoms coming from the carboxylic groups of $\mathrm{BDC}$ while the remaining two come from BPNO) interconnected by both BDC and BPNO ligands (Fig. 1a). It should be mentioned that typical for MIL-53 family, in which the metal cations are mainly +3 metallic cations, the $\mathrm{M}^{\mathrm{III}} \mathrm{O}_{6}$ octahedra share the axial $\mu_{2}-\mathrm{OH}$ to produce an almost linear chain and all the equatorial oxygen atoms come from the dicarboxylate ligands. However, for our divalent metal cations based MIL-53 analogues, two $\mu_{2}-\mathrm{O}$ atoms locating in the two axial positions of the $\mathrm{M}^{\mathrm{II}} \mathrm{O}_{6}$ octahedra along the infinite chains come from BDC and BPNO ligands. As we mentioned earlier, ${ }^{10}$ both cis- and trans- $\mathrm{M}^{\mathrm{II}} \mathrm{O}_{6}$ octahedra could be formed if the six oxygen atoms are differentiated when taking the two ligands into consideration. The coexistence of cis- and trans- $\mathrm{MgO}_{6}$ octahedra in the $\mathrm{Mg}-\mathrm{O}$ chains corrugates the infinite chains and results in a zig-zag configuration (Fig. 1b). Along its $a$ direction, there are typical one-dimensional (1D) rhombic channels with dimensional size of $13.92 \times 16.89 \AA$ (Fig. 1c). Its accessible solvent portion was estimated by PLATON to be about $42.9 \%$ of the total crystal volume $\left(3308.8 \AA^{3}\right) .{ }^{14}$ The accommodated DMF molecules form dimers within the channels and interact with BPNO linkers of the framework via strong $\mathrm{C}-\mathrm{H} \cdots \mathrm{O}$ hydrogen bonds (Fig. S1†).

\section{Gas adsorption, XRD, FT-IR and TGA}

Once the occluded DMF molecules were removed from $\mathbf{1}$, to give 1a, a contraction of the cell volume from $3308.8 \AA^{3}$ of 1 to $3166 \AA^{3}$ of 1 a was observed (see Table $\mathrm{S} 2 \dagger$ ). The porosity of 1a was confirmed by $\mathrm{CO}_{2}$ sorption measurements at $273 \mathrm{~K}$. As

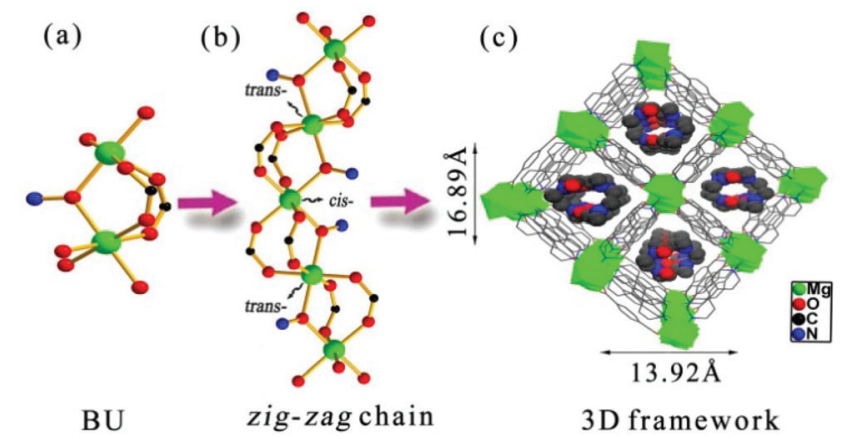

Fig. 1 The framework structure of 1 constructed by the characteristic building units (BUs are linked into a 1D zig-zag chain and further connected into a 3D structure). The occluded molecules in 1 are DMF molecules. shown in Fig. S2, $\uparrow$ there is a pronounced hysteresis behavior, which accounts for a moderate adsorption capacity of $\sim 17.9 \mathrm{~cm}^{3} \mathrm{~g}^{-1}$ at $P / P^{\circ}=0.030$. The observed hysteresis of the $\mathrm{CO}_{2}$ sorption isotherm may be attributed to the relatively strong adsorbent-adsorbate interactions. However, no nitrogen diffusion was observed at $77 \mathrm{~K}$, despite the stable framework and adequate effective pore size. ${ }^{15}$ The $\mathrm{CO}_{2}$ selectivity may be due to the higher kinetic energy of $\mathrm{CO}_{2}$ molecules at $273 \mathrm{~K}$, which permits diffusion of $\mathrm{CO}_{2}$ molecules.

The X-ray powder diffraction pattern of Mg-MIL-53 and 1a loaded with different guest molecules (NB, NM and NE) are shown in Fig. S3. $\dagger$ The XRD patterns for 1, 1a, 2, 3, and 4 are well crystalline and the peaks obtained are in good agreement with each other.

We then monitored different guest molecule-exchange experiments by FT-IR spectroscopy (Fig. S4 $\dagger$ ). We observed that all five compounds show characteristic bands between 3600 and $3200 \mathrm{~cm}^{-1}$, which are due to $\nu(\mathrm{O}-\mathrm{H})$ vibrations of the water molecules. Weak $\nu(\mathrm{C}-\mathrm{H})$ bands of the free guest molecules are observed in the region of $3050-2850 \mathrm{~cm}^{-1}$. The characteristic bands at $\sim 1649$ and $\sim 1496 \mathrm{~cm}^{-1}$ could be ascribed to the existence of the asymmetric and symmetric stretch vibrations of the dicarboxylate groups. Moreover, the typical vibration band at $1522 \mathrm{~cm}^{-1}$ of 2,3 and 4 is for the $\mathrm{N}=\mathrm{O}$ stretching vibrations. ${ }^{6}$ Finally, the $\mathrm{C}=\mathrm{O}$ stretching frequency corresponding to DMF is observed at about $1668-1665 \mathrm{~cm}^{-1}$.

Thermogravimetric analysis (TGA) of 1, 1a, 2, 3, 4 and Mn/ Co-MIL-53 was investigated using polycrystalline samples under nitrogen atmosphere from 30 to $800{ }^{\circ} \mathrm{C}$ (Fig. S5 and S6 $\dagger$ ). From the TGA curves of 1a and nitromethane (NM) exchanged product $\left.\left[\mathrm{Mg}_{2}(\mathrm{BDC})_{2}(\mathrm{BPNO})\right] \cdot 2 \mathrm{NM}\right]$ (3), it can be seen that the framework begins to decompose around $280{ }^{\circ} \mathrm{C}$. The weight loss between $280^{\circ} \mathrm{C}$ and $350{ }^{\circ} \mathrm{C}$ can be attributed to the removal of BPNO molecules, for all seven compounds. The temperature range for losing BPNO molecules is higher than the range of $230-310{ }^{\circ} \mathrm{C}$ for $\mathrm{H}_{2}(\mathrm{BPDO})_{4} \mathrm{Cl}_{2}$ due to the formation of MOF (BPDO is another abbreviation for 4,4'-dipyridyl- $N, N^{\prime}$-dioxide used in literature). ${ }^{16}$ The BDC linkers would decompose at temperatures above $520{ }^{\circ} \mathrm{C}$ and all seven compounds would convert into crystalline metal oxides. It must be noted that about an $8 \%$ weight loss was observed from room temperature to $180{ }^{\circ} \mathrm{C}$ for the as-synthesized 1a samples, owing to the occluded DMF residues on the surface of $\mathbf{1 a}$.

\section{Selective adsorption and separation of NB, NM and NE by Mg-MIL-53 analogue}

We initially intended to use $\mathbf{1 a}$ as a sorbent for the adsorption and separation of C6-C8 aromatics via the SC-SC transformation as we did with the Mn-MIL-53 analogue. It turned out to be unsuccessful due to the collapse of $\mathbf{1 a}$ in benzene, toluene and chlorobenzene. We then sought other chemicals to justify its adsorption capability. Fortunately, when 1a was immersed into NB liquid, it did adsorb NB. The extension of this process to aliphatic nitro-organic liquid explosives including NM, NE and two nitropropane (NP) isomers was also carried out. 


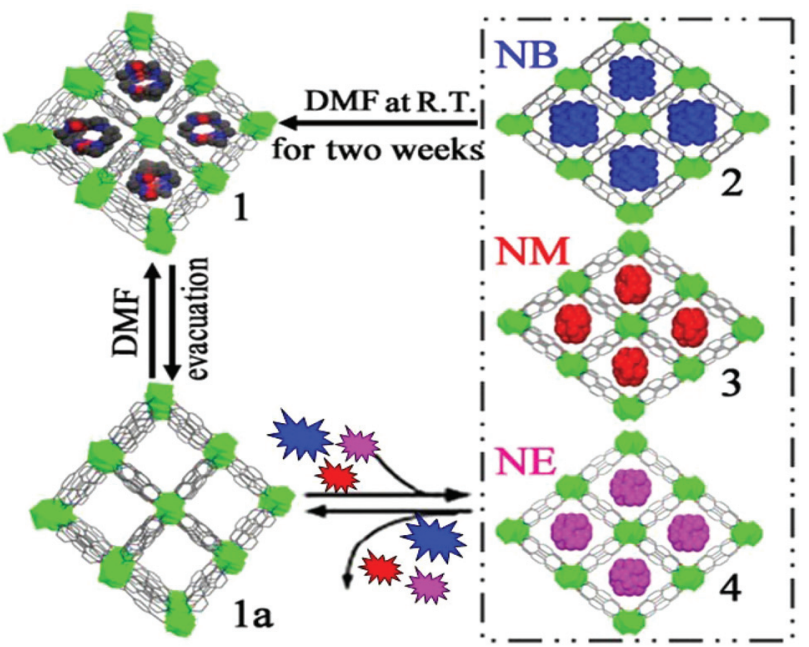

Fig. 2 Perspective views of the 3D open framework with 1D channel in 1 (with guest DMF molecules) and desolvated 1a; Reversibly selective adsorption of NB ( 2 , in blue), NM (3, in red) and NE (4, in purple) by $1 a$; Crystals of 1 could be regenerated from 2, 3 and 4 by soaking them in DMF for two weeks at room temperature. Color code for 1: green, Mg; red, O; blue, N; $50 \%$ gray, C.

Except for the two NP isomers, both NM and NE could be intercalated into the voids of $\mathbf{1 a}$. The resultant three hostguest complexes 2, 3 and 4 correspond to $\mathrm{NB}, \mathrm{NM}$ and $\mathrm{NE}$ intercalated products, respectively (Fig. 2). Single crystal structural analysis (Table S2 $\dagger$ ) shows that the presence of different nitro explosives within the channels does not have a profound effect on the architecture of the framework of 1a. Akin to original guest DMF molecules, the three intercalated liquid nitro explosive molecules fill the channels pairwise and there are two symmetrically equivalent positions along the 1D channels for accommodating the dimeric guest molecules (Fig. S7†).

Attempts to investigate preferential adsorption of one guest molecule over another among the three explosives by $\mathbf{1 a}$ have been also made. When crystals of $1 \mathrm{a}$ were immersed into three binary liquid explosive solutions (e.g. NB + NM, NB + NE and $\mathrm{NM}+\mathrm{NE}$, in which equal volumes of the two different liquid were mixed together) crystals of 2 were yielded in $\mathrm{NB}+\mathrm{NM}$ and NB + NE mixtures while crystals of 3 were harvested from the NM + NE mixed solution. When crystals of 1a were soaked in a tertiary mixture of the three explosives with an equal volume of each nitro compound, as expected, only NB was taken up to yield crystals of 2 . All of these experimental results clearly suggest that the preferential adsorption among the three explosives follows the trend of $\mathrm{NB}>\mathrm{NM}>\mathrm{NE}$, when equal volumes of these molecules were mixed together.

It should be noted that by varying the volume ratio of the nitro explosives in the solvent mixture, the above observed preferential adsorption trend was not always obeyed. In a mixture of NM + NB with a volume ratio of NM to NB of at least $15: 1$, NM was incorporated into 1a. Similarly, crystals of 4 with NE as guest molecules were formed in a system of $\mathrm{NE}+\mathrm{NB}$ or $\mathrm{NE}$ $+\mathrm{NM}$ when the volume ratio of NE to NB or NM was $55: 1$ or $35: 1$, respectively. The results are shown in Table 1 .
Table 1 Preference of the nitro explosives for 1a with variation of volume ratio

\begin{tabular}{ll} 
NB/NM/NE ratio & Compound formed \\
\hline $1: 1: 0$ & 2 \\
$1: 0: 1$ & 2 \\
$0: 1: 1$ & 3 \\
$1: 1: 1$ & 2 \\
$1: 15: 0$ & 3 \\
$1: 0: 55$ & 4 \\
$0: 1: 35$ & 4
\end{tabular}

\section{Photoluminescence properties}

Solid photoluminescence (PL) spectra were recorded using powder samples of $\mathbf{1}$ and $\mathbf{1 a}$ in thin-layer forms (Fig. 3 and S8 $\dagger$ ). Both spectra show one strong blue luminescence at around $421 \mathrm{~nm}$ and two weak shoulder peaks at $387 \mathrm{~nm}$ and $453 \mathrm{~nm}$, upon excitation at $305 \mathrm{~nm}$ at room temperature. In addition, the emissions of the two free ligands are at $407 \mathrm{~nm}$ for $\mathrm{H}_{2} \mathrm{BDC}\left(\lambda_{\mathrm{ex}}=345 \mathrm{~nm}\right)$ and $459 \mathrm{~nm}$ for BPNO $\left(\lambda_{\mathrm{ex}}=\right.$ $396 \mathrm{~nm})$. Therefore, the two weak shoulder peaks might
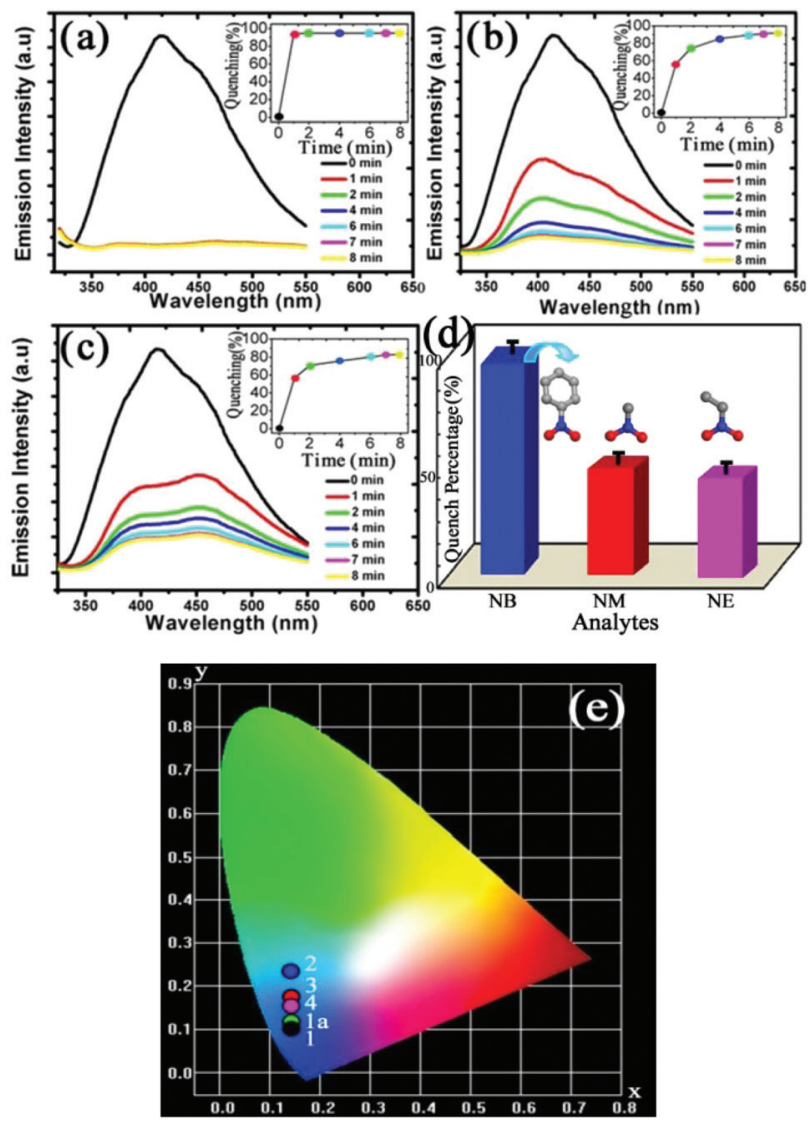

Fig. 3 Time-dependent fluorescence spectra of 1a upon exposure to saturated vapors of NB (a), NM (b) and NE (c), insets: time-dependent fluorescence quenching (\%) of the three explosives. (d) Comparison of the fluorescence quenching efficiency of 1a upon exposure to vapors of different analytes for 1 minute. (e) The corresponding $\mathrm{CIE}$ chromaticity diagram of luminescence for 1 (black), 1a (green), 2 (blue), 3 (red) and 4 (purple). 
originate from the two ligands although they showed slight blue shifts. Such observations are likely to be due to the synergistic effect between the neighboring ligands BDC and BPNO. The enhancement of luminescence upon coordination may be attributed to their increased rigidity after coordination. ${ }^{17}$

From the insets of Fig. $3 \mathrm{a}-\mathrm{d}$, the order of quenching efficiency for the selected nitro explosives also follows NB > $\mathrm{NM}>\mathrm{NE}$, similar to the preferential adsorption trend of all three explosives by 1a. As shown in Fig. 3e, their corresponding Commission Internationale De L'Eclairage (CIE) chromaticity coordinates are $(0.14,0.11)$ for $1,(0.14,0.12)$ for $1 \mathrm{a},(0.14$, $0.24)$ for $2,(0.14,0.14)$ for 3 and $(0.14,0.16)$ for $\mathbf{4}$. All of these coordinates lie in the blue region, except for $\mathbf{4}$ which belongs to the greenish-blue area. Besides, once the adsorption equilibriums were reached after $c a .8$ minutes of exposure, the quenching efficiency of NB $(94.7 \%)$ was comparable to those of NM (92.1\%) and NE (83.3\%). Noticeably, the fluorescence of 2, 3 and 4 could be recovered when the three guest molecules were removed or exchanged by DMF molecules (Fig. S9†). As an illustrative example, three consecutive cycles of the quench-regeneration process for 2,3 and 4 are plotted in Fig. S10. $\dagger$ These data suggest that the Mg-MIL-53 analogue is a potential candidate for reversible detection of the trace vapors of high explosives via fluorescence quenching techniques.

\section{Preferential adsorption of liquid nitro explosive by Mg-MIL-53}

To interpret this preferential adsorption, the guest-guest and guest-host interactions, including both hydrogen bonding and $\pi-\pi$ interactions, were carefully examined on the basis of structural analysis using single crystal diffraction data (Fig. 4 and Table 2). Firstly, all three occluded nitro explosives in 2, 3, and 4 tend to form antiparallel dimers to facilitate the dipoledipole interactions (Fig. S7†). For NB molecules in 2, there is an intermolecular parallel displaced (PD) $\pi-\pi$ interaction within the dimer (centroid-to-centroid distance $3.608 \AA$ ). In addition, each NB molecule interacts with one phenyl ring of $\mathrm{BDC}$ in the framework through nearly isoenergetic T-shaped $\mathrm{CH}-\pi$ interaction $\left(\mathrm{T}_{1}=3.615 \AA, \mathrm{T}_{2}=3.804 \AA\right.$ and $\mathrm{T}_{3}=3.943 \AA$,
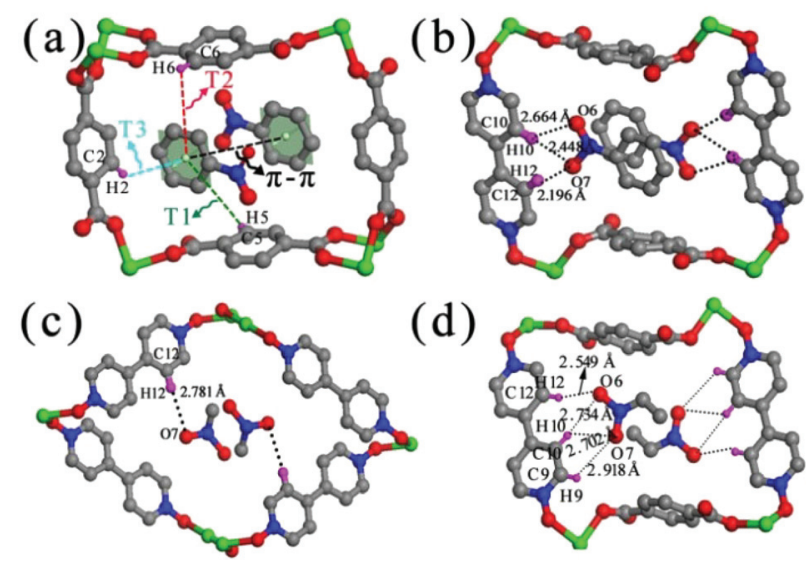

Fig. 4 The $\mathrm{C}-\mathrm{H} \cdots \pi$ (T-shaped) and $\pi-\pi$ interactions in 2 (a), and interhost-guest hydrogen-bonding systems in 2 (b), 3 (c), and 4 (d).
Table 2 Relevant $\mathrm{C}-\mathrm{H} \cdots \pi$ (T-shaped) interactions, $\pi-\pi$ interactions and hydrogen-bonding geometries $\left(\AA^{\circ},{ }^{\circ}\right)$ found in 2-4

\begin{tabular}{|c|c|c|c|}
\hline \multicolumn{3}{|l|}{$\mathrm{C}-\mathrm{H} \cdots \pi$} & $d(\mathrm{H} \cdots \pi)$ \\
\hline \multicolumn{4}{|l|}{2} \\
\hline \multirow{4}{*}{\multicolumn{3}{|c|}{$\begin{array}{l}\mathrm{C} 5-\mathrm{H} 5 \cdots \pi \text { of }(\mathrm{C} 14, \mathrm{C} 15, \mathrm{C} 16, \mathrm{C} 17, \mathrm{C} 18 \text { and } \mathrm{C} 19) \\
\mathrm{C} 6-\mathrm{H} 6 \cdots \pi \text { of }(\mathrm{C} 14, \mathrm{C} 15, \mathrm{C} 16, \mathrm{C} 17, \mathrm{C} 18 \text { and } \mathrm{C} 19) \\
\mathrm{C} 2-\mathrm{H} 2 \cdots \pi \text { of }(\mathrm{C} 14, \mathrm{C} 15, \mathrm{C} 16, \mathrm{C} 17, \mathrm{C} 18 \text { and } \mathrm{C} 19)\end{array}$}} & \multirow{4}{*}{$\begin{array}{l}3.615\left(\mathrm{~T}_{1}\right) \\
3.804\left(\mathrm{~T}_{2}\right) \\
3.943\left(\mathrm{~T}_{3}\right) \\
3.608\end{array}$} \\
\hline & & & \\
\hline & & & \\
\hline & & & \\
\hline $\mathrm{D}-\mathrm{H} \cdots \mathrm{A}$ & $d(\mathrm{H} \cdots \mathrm{A})(\AA)$ & $d(\mathrm{D} \cdots \mathrm{A})(\AA)$ & $\angle \mathrm{DHA}\left(^{\circ}\right)$ \\
\hline \multicolumn{4}{|l|}{2} \\
\hline 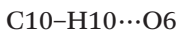 & 2.664 & 3.390 & 135.469 \\
\hline 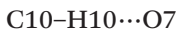 & 2.488 & 3.414 & 173.979 \\
\hline C12-H12 ‥ & 2.196 & 3.111 & 168.245 \\
\hline 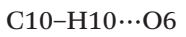 & 2.664 & 3.390 & 135.469 \\
\hline \multicolumn{4}{|l|}{3} \\
\hline 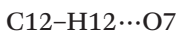 & 2.781 & 3.711 & 166.955 \\
\hline \multicolumn{4}{|l|}{4} \\
\hline C9-H9…O7 & 2.918 & 3.495 & 121.548 \\
\hline C12-H12 ‥ & 2.549 & 3.461 & 166.121 \\
\hline 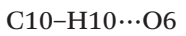 & 2.734 & 3.654 & 170.115 \\
\hline 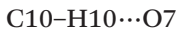 & 2.702 & 3.391 & 131.489 \\
\hline
\end{tabular}

Fig. 4a) and one BPNO molecule via four hydrogen bonds (Fig. 4b). Compared to the well-known range of 3.3-3.8 $\AA$ for $\pi-\pi$ interactions, there is only a $\mathrm{T}_{1}$-shaped $\mathrm{CH}-\pi$ interaction between each NB molecule and the phenyl ring of the BDC linker within this range. For NM and NE molecules in $\mathbf{3}$ and $\mathbf{4}$, no guest-guest $\pi-\pi$ interactions or guest-host $\mathrm{CH}-\pi$ interactions exist. Only guest-host hydrogen bonding between NM or NE and BPNO was found for both these molecules and the numbers of hydrogen bonds for each NM and NE molecule is one and four, respectively (Fig. 4c and d). Although NE has more hydrogen bonds with BPNO than NM, the adsorption of NM by 1a is preferred to NE when an equal volume of the two nitro-organics was mixed together. This phenomenon might be explained from the perspective of their differing steric hindrance during their diffusion into the pore.

\section{The mechanism of the fluorescence quenching effect for the adsorption of the three nitro explosives into desolvated Mg-MIL-53}

With the diffusion of the vapors of the three nitro explosives into the pores of 1a, time-dependent fluorescence intensities decreased and eventually the framework luminescences were quenched. ${ }^{6,18}$ The observed fluorescence quenching can be explained by an electron transfer donor-acceptor mechanism. Obviously, the electron transfer that could originate from the intraligand emission or weak LLCT process is faster than those of the ILCT process. This is evidenced by the fast quenching of emissions at $421 \mathrm{~nm}$ for all guest molecules as shown in Fig. 3a-c. However, the electron transfer originating from the ILCT process is relatively slower and varies with the guest molecules. For NB, the two emissions at $387 \mathrm{~nm}$ and $453 \mathrm{~nm}$ disappeared almost simultaneously with the major emission peak in Fig. 3a. This could be attributed to the formation of delocalized conjugated $\pi-\pi$ interactions between NB and the two ligands. In the case of NM and NE, only hydrogen 
bonding interactions were formed between guest molecules and the BPNO ligands. The intensities of the two shoulder emission peaks decreased much more slowly compared with that of the major emission peak. Due to the lack of direct interactions between BDC and NM or NE guest molecules, the peak at $387 \mathrm{~nm}$ for both cases (Fig. $3 \mathrm{~b}$ and c) has a similar decreasing trend. However, the fluorescence shoulder peak at $453 \mathrm{~nm}$ does not exhibit an appreciable quench effect upon exposure to the NE vapor in comparison with NM. This is likely due to the fact that NM and NE represent one of the highly volatile explosives, with vapor pressure of $36000 \mathrm{ppm}$ and $20183 \mathrm{ppm}$ at room temperature, respectively. Moreover, although the vapor pressure of $\mathrm{NE}$ is comparable to that of NM, the quenching efficiency of NE is significantly less because NE molecules have one more $-\mathrm{CH}_{2}$ - group, which hinders a fast long-range electron transfer between BPNO and NE interactions. ${ }^{19}$ Until now, there have been only a few materials reported that could be used for the fluorescence-quenching based vapor detection of NM and NE under ambient conditions, because of their high volatility. ${ }^{20}$

\section{Conclusion}

We have successfully extended the synthetic strategy for +2 transition metal cation-based MIL-53 analogues to a lightweight metal based three-dimensional framework of $\mathbf{M g}$ MIL-53, using mixed solvents via a solvothermal process. The desolvated Mg-MIL-53 demonstrated a reversible selective adsorption and separation of liquid nitro explosives including $\mathrm{NB}, \mathrm{NM}$ and NE through SC-SC transformations. Its intrinsic fluorescence could be quenched upon the adsorption of the three small explosives and the quenching efficiency towards nitroaromatic (NB) and nitroaliphatic (NM and NE) explosives varied with the guest molecules. Single crystal structure analysis revealed that different guest-guest and guest-host interactions among the different nitro explosives can be used to interpret both the preferential adsorption of one nitro-organic explosive over the other and their different quenching efficiencies.

\section{Acknowledgements}

This work is supported by NSFC through the Major Research Plan (91022005), NSFC (21171159) and Innovative Research Groups (20921002). Fanglin Chen is supported by the HeteroFoaM Center, an Energy Frontier Research Center funded by the US Department of Energy (DoE), Office of Science, Basic Energy Sciences (BESs), under Award No. DE-SC0001061.

\section{Notes and references}

1 M. D. Allendorf, C. A. Bauer, R. K. Bhaktaa and R. J. T. Houk, Chem. Soc. Rev., 2009, 38, 1330-1352.
2 (a) J. Rocha, L. D. Carlos, F. A. A. Paz and D. Ananias, Chem. Soc. Rev., 2011, 40, 926-940; (b) Y.-J. Cui, Y.-F. Yue, G.-D. Qian and B.-L. Chen, Chem. Rev., 2012, 112, 1126-1162.

3 (a) L. E. Kreno, K. Leong, O. K. Farha, M. Allendorf, R. P. Van Duyne and J. T. Hupp, Chem. Rev., 2012, 112, 1105-1125; (b) B.-L. Chen, S.-G. Xiang and G.-D. Qian, Acc. Chem. Res., 2010, 43, 1115-1124.

4 (a) A. Y. Robin and K. M. Fromm, Coord. Chem. Rev., 2006, 250, 2127-2157; (b) D. M. Bassani, L. Jonusauskaite, A. Lavie-Cambot, N. D. McClenaghan, J.-L. Pozzo, D. Ray and G. Vives, Coord. Chem. Rev., 2010, 254, 2429-2445.

5 R. Meyer, J. Kohler and A. Homburg, Explosives, Wiley-VCH Verlag GmbH, Weinheim, 2002.

6 (a) J. I. Steinfeld and J. Wormhoudt, Annu. Rev. Phys. Chem., 1998, 49, 203-232; (b) S. W. Thomas, G. D. Joly and T. M. Swager, Chem. Rev., 2007, 107, 1339-1386; (c) Y. S. Xue, Y. He, L. Zhou, F. J. Chen, Y. Xu, H. B. Du, X. Z. You and B. Chen, J. Mater. Chem. A, 2013, 1, 45254530; (d) S. S. Nagarkar, B. Joarder, A. K. Chaudhari, S. Mukherjee and S. K. Ghosh, Angew. Chem., 2013, 125, 2953-2957, (Angew. Chem., Int. Ed., 2013, 52, 2881-2885); (e) S. R. Zhang, D. Y. Du, J. S. Qin, S. J. Bao, S. L. Li, W. W. He, Y. Q. Lan, P. Shen and Z. M. Su, Chem. - Eur. J., 2014, 20, 3589-3594.

7 (a) Y. Salinas, R. Martínez-Máñez, M. D. Marcos, F. Sancenón, A. M. Costero, M. Parraad and S. Gil, Chem. Soc. Rev., 2012, 41, 1261-1296; (b) M. E. Germain and M. J. Knapp, Chem. Soc. Rev., 2009, 38, 2543-2555.

8 (a) S. Pramanik, C. Zheng, X. Zhang, T. J. Emge and J. Li, J. Am. Chem. Soc., 2011, 133, 4153-4155; (b) H. Xu, F. Liu, Y.-J. Cui, B.-L. Chen and G.-D. Qian, Chem. Commun., 2011, 47, 3153-3155; (c) B. Gole, A. K. Bar and P. S. Mukherjee, Chem. Commun., 2011, 47, 12137-12139; (d) Z.-J. Zhang, S.-C. Xiang, X.-T. Rao, Q. Zheng, F. R. Fronczek, G.-D. Qian and B.-L. Chen, Chem. Commun., 2010, 46, 7205-7207; (e) A.-J. Lan, K.-H. Li, H.-H. Wu, D. H. Olson, T. J. Emge, W. Ki, M.-C. Hong and J. Li, Angew. Chem., 2009, 121, 2370-2374, (Angew. Chem., Int. Ed., 2009, 48, 2334-2338).

9 (a) H.-X. Deng, S. Grunder, K. E. Cordova, C. Valente, H. Furukawa, M. Hmadeh, F. Gándara, A. C. Whalley, Z. Liu, S. Asahina, H. Kazumori, M. O'Keeffe, O. Terasaki, J. F. Stoddart and O. M. Yaghi, Science, 2012, 336, 10181023; (b) T. M. McDonald, W. R. Lee, J. A. Mason, B. M. Wiers, C. S. Hong and J. R. Long, J. Am. Chem. Soc., 2012, 134, 7056-7065; (c) X. Zhao, T. Wu, S.-T. Zheng, L. Wang, X.-H. Bu and P.-Y. Feng, Chem. Commun., 2011, 47, 5536-5538; (d) M. Dincǎ and J. R. Long, J. Am. Chem. Soc., 2005, 127, 9376-9377.

10 (a) G.-H. Xu, X.-G. Zhang, P. Guo, C.-L. Pan, H.-J. Zhang and C. Wang, J. Am. Chem. Soc., 2010, 132, 3656-3657; (b) D. Liu, Y.-X. Liu, G.-H. Xu, G.-H. Li, Y. Yu and C. Wang, Eur. J. Inorg. Chem., 2012, 4413-4417; (c) Y.-X. Liu, D. Liu, Y. Yu, J. Xu, X.-H. Han and C. Wang, CrystEngComm, 2013, 15, 10611-10617.

11 G. Férey and C. Serre, Chem. Soc. Rev., 2009, 38, 1380-1399. 
12 (a) A. Shigematsu, T. Yamada and H. Kitagawa, J. Am. Chem. Soc., 2011, 133, 2034-2036; (b) D. Kolokolov, H. Jobic, A. G. Stepanov, V. Guillerm, T. Devic, C. Serre and G. Férey, Angew. Chem., 2010, 122, 4901-4904, (Angew. Chem., Int. Ed., 2010, 49, 4791-4794); (c) F. X. Coudert, C. Mellot-Draznieks, A. H. Fuchs and A. Boutin, J. Am. Chem. Soc., 2009, 131, 11329-11331.

13 K. Barthelet, J. Marrot, D. Riou and G. Férey, Angew. Chem., 2002, 114, 291-294, (Angew. Chem., Int. Ed., 2002, 41, 281-284).

14 A. L. Spek, PLATON, A Multipurpose Crystallographic Tool, Utrecht University, The Netherlands, 1999.

15 T. Maji, R. Matsuda and S. Kitagawa, Nat. Mater., 2007, 6, 142-148.

16 N. Leblanc, M. Allain, N. Mercier and E. Cariati, Cryst. Growth Des., 2011, 11, 5200-5205.

17 M.-X. Jiang, C.-H. Zhan, Y.-L. Feng and Y.-Z. Lan, Cryst. Growth Des., 2010, 10, 92-98.

18 (a) Y.-K. Che, D. E. Gross, H.-L. Huang, D.-J. Yang, X.-M. Yang, E. Discekici, Z. Xue, H.-J. Zhao, J. S. Moore and
L. Zang, J. Am. Chem. Soc., 2012, 134, 4978-4982; (b) D. T. McQuade, A. E. Pullen and T. M. Swager, Chem. Rev., 2000, 100, 2537-2574.

19 E. Göransson, J. Boixel, J. Fortage, D. Jacquemin, H. C. Becker, E. Blart, L. Hammarström and F. Odobel, Inorg. Chem., 2012, 51, 11500-11512.

20 (a) V. M. Mochalova and A. V. Utkin, AIP Conf. Proc., 2012, 1426, 303-306; (b) C.-Y. Zhang, Y.-K. Che, Z.-X. Zhang, X.-M. Yang and L. Zang, Chem. Commun., 2011, 47, 2336-2338; (c) C.-Y. Zhang, C.-Y. Che, X.-M. Yang, B. R. Bunes and L. Zang, Chem. Commun., 2010, 46, 5560-5562; (d) T. K. Kim, J. H. Lee, D. Moon and H. R. Moon, Inorg. Chem., 2013, 52, 589-595; (e) X.-H. Zhou, H.-H. Li, H.-P. Xiao, L. Li, Q. Zhao, T. Yang, J.-L. Zou and W. Huang, Dalton Trans., 2013, 42, 5718-5723.

21 P. G. Simpson, J. V. Quagliano and A. Vinciguerra, Inorg. Chem., 1963, 2, 282-286.

22 G. M. Sheldrick, SHELXL-97, A Program for Crystal Structure Refinement, University of Geottingen, Germany, 1997. 